\title{
OPTIMALISASI BUDIDAYA TOGA DENGAN PEMBUATAN PESTISIDA ALAMI DAN PEMANFAATAN TANAMAN REFUGIA
}

\author{
Prashinta Nita Damayanti'1), Nastiti Utami1), Iwan Setiawan'1), Nur Rasmi Safitri'1), \\ Renatha Audya Larasati ${ }^{1)}$, Winda Vionia Seviana ${ }^{1}$, Elen Arditawati ${ }^{1}$, Mutiara Kartika Sari') \\ 1)Program Studi S1 Farmasi, Sekolah Tinggi IImu Kesehatan Nasional, Surakarta, Jawa Tengah, Indonesia \\ Corresponding author: Nastiti Utami \\ E-mail : prashintanita@gmail.com
}

\section{Diterima 10 November 2021, Disetujui 17 November 2021}

\begin{abstract}
ABSTRAK
Kelompok tani dan masyarakat pedesaan berperan dalam kemandirian kesehatan melalui pengembangan TOGA (Tanaman Obat Keluarga). Namun ada beberapa kendala dalam budidaya TOGA, salah satunya adalah hama tanaman sehingga perlunya dilakukan penanganan hama dengan tepat dan aman dengan pembuatan pestisida alami dan pemanfaatan tanaman refugia. Kegiatan ini bertujuan untuk meningkatkan pengetahuan masyarakat Desa Laban, Mojolaban, Sukoharjo dalam pembuatan pestisida alami dari daun pepaya dan pemanfaatan tanaman refugia dalam rangka optimalisasi budidaya toga. Metode yang digunakan adalah ceramah dan diskusi. Penyuluhan dilaksanakan melalui whatsapp group. Evaluasi keberhasilan dilaksanakan dengan pemberian pretest dan postest sebelum dan sesudah penyampaian materi serta survei kepuasan mengenai tema dan kegiatan pengabdian melalui pengisian kuesioner. Hasil pengabdian menunjukkan adanya peningkatan pengetahuan masyarakat tentang optimalisasi budidaya TOGA dengan cara pembuatan pestisida alami serta penanaman tanaman refugia sebagai pengendali hama, hal tersebut dapat dilihat dari nilai ratarata pretest dan posttest yang semula 53,71 menjadi 84,00 . Hasil evaluasi kepuasan peserta terhadap tema dan kegiatan pengabdian menunjukkan bahwa dari 35 peserta, $42,9 \%$ peserta menyatakan sangat puas, $48,6 \%$ peserta menyatakan puas, dan $8,6 \%$ peserta menyatakan cukup puas dengan kegiatan dan tema pengabdian masyarakat ini.
\end{abstract}

Kata kunci: budidaya; toga; pestisida; refugia.

\begin{abstract}
Farmer groups and rural communities have a role in health independence through the development of medicinal plants. However, there are several detrimental factors in medicinal plants cultivation, such as plant pests, so we need an proper pest management by making natural pesticides and using refugia plants. This community service program aims to increase the knowledge of the people of Laban Village in context of manufacture of natural pesticides from papaya leaves and the use of refugia plants in order to optimize the cultivation of medicinal plants. The methods used are counceling and discussions via whatsapp group. Evaluation of program was carried out by giving a pretest and posttest and survey of satisfaction through filling out questionnaires. The results of the programs show that there is an increase in participants knowledge about optimizing medicinal plants cultivation by making natural pesticides and planting refugia plants as pest control, as indicated by an increase value of the pretest and posttest from 53.71 to 84.00 . The results of the evaluation of participants satisfaction with program showed that $42.9 \%$ of the participants said it was very good, $48.6 \%$ of the participants said good, and $8.6 \%$ of the participants said it was good enough.
\end{abstract}

Keywords: cultivation; medicinal plants; pesticides; refuge.

\section{PENDAHULUAN}

Indonesia merupakan salah satu negara agraris. Banyak macam tanaman yang dapat tumbuh di Indonesia. Tanaman tidak hanya bermanfaat sebagai bahan makanan ataupun sebagai hiasan. Tanaman juga banyak bermanfaat untuk penyembuhan dan pengobatan. Tanaman obat dapat dibudidayakan sendiri di rumah atau biasa disebut dengan apotek hidup. Tanaman obat keluarga (TOGA) atau biasa disebut dengan apotek hidup adalah kegiatan budidaya tanaman obat di halaman rumah atau pekarangan sebagai antisipasi pencegahan maupun mengobati secara mandiri menggunakan tanaman obat yang ada.

Menurut Survei Subdit Aneka Tanaman dalam (Lestari, 2019), total kebutuhan tanaman 
TOGA dalam negeri adalah $36.200 \mathrm{~kg} / \mathrm{bulan}$. Dari sisi kebutuhan lokal, demand komoditas tanaman obat tradisional semakin meningkat seiring dengan peningkatan jumlah tanaman obat tradisional. Pabrik-pabrik penghasil jamu, obat-obatan dan kosmetika, bahan baku obat tradisional (jamu), bahan makanan, minuman dan kosmetik digunakan sebagai bahan baku, sehingga budidaya TOGA memberikan peluang yang sangat baik bagi peningkatan ekonomi masyarakat. Dengan memahami manfaat dan khasiat dan jenis tanaman tertentu, tanaman obat menjadi pilihan keluarga dalam memilih obat alami yang aman (Savitri A, 2016).

Kelompok Tani Wanita (KWT) Desa Laban yang berada di Kelurahan Mojolaban memiliki lahan kebun yang luas namun belum dimanfaatkan secara maksimal. Masyarakat di Desa Laban beberapa kali menanam TOGA tetapi hasilnya tidak maksimal, bahkan tanaman sering mati (rusak). Dalam proses budidaya tanaman ada beberapa faktor merugikan dalam budidaya tanaman yang sering dijumpai yakni salah satunya adalah hama tanaman, sehingga perlunya dilakukan Penanagan Organisme pengganggu tanaman (OPT) yang tepat. Penanganan organisme pengganggu tanaman (OPT) yang kurang tepat mengakibatkan kerugian yang cukup besar baik berupa kehilangan hasil (kuantitas) dan penurunan mutu (kualitas) tanaman (Septariani DN et al., 2019) Penggunaan pestisida kimia yang tidak tepat dapat memberikan dampak seperti resistensi hama. Selain itu residu pestisida yang terdapat pada produk pertanian sangat berbahaya jika dikonsumsi dalam jangka waktu yang panjang. Alternatif yang dapat diberikan sebagai upaya strategi budidaya berdasarkan keragaman hayati maka perlu dilakukan pengendalian hama yang ramah pada lingkungan (Hasfita et al., 2019).

Salah satu alternatif pengembangan pestisida berwawasan lingkungan yaitu dengan menggunakan pestisida nabati yang berasal dari jenis tumbuh-tumbuhan. Beberapa jenis tumbuhan seperti daun gamal, pacar cina, daun mimba, biji jarak, daun sirsak dan daun pepaya dianalisa dapat berfungsi sebagai pestisida. Pada percobaan ini akan dicoba teliti pestisida nabati yang berasal dari daun pepaya. Mengingat daun pepaya sangat mudah didapatkan dan jarang dimanfaatkan oleh masyarakat. Pestisida daun pepaya diyakini mempunyai efektifitas yang tinggi dan dampak spesifik terhadap organisme pengganggu dan residunya dapat terurai menjadi senyawa yang tidak beracun sehingga ramah lingkungan. Pada daun pepaya zat aktifnya tidak membahayakan bagi manusia dan hewan (Yogiraj, 2015). Daun pepaya mengandung enzim papain, alkaloid karpaina, pseudo karpaina, glikosid, karposid, dan saponin (Muchlisah 2004). Selain itu, residunya terurai menjadi senyawa yang tidak beracun sehingga aman bagi lingkungan. Hasil yang diperoleh diharapkan dapat memberi pengetahuan kepada masyarakat tentang pemanfaatan bahan alam untuk pembuatan pestisida serta diperoleh informasi tentang prosedur pembuatan pestisida dari daun pepaya yang efektif.

Selain pembuatan pestisida nabati, upaya dengan Pengendalian Hama Terpadu (PHT) yang lebih ramah lingkungan telah banyak dilakukan (Aqilah, 2016). Salah satu pengendalian hama yang ramah lingkungan adalah dengan cara pemanfaatan tanaman refugia sebagai perlindungan bagi musuh alami dan predator pada tanaman. Tanaman Refugia adalah pertanaman beberapa jenis tanaman yang dapat menyediakan tempat perlindungan, sumber pakan atau sumberdaya yang lain bagi musuh alami seperti predator dan parasitoid (Nentwig, 1998; Wratten et al., 2004). Umumnya tanaman refugia ditanam di pinggir guludan atau diluar pertanaman secara memanjang dan berbunga mencolok. Serangga-serangga musuh alami seperti kumbang, lebah, semut, dan serangga hama seperti thrips, kupu-kupu sangat tertarik dengan tanaman yang berbunga dengan warna mencolok serta berbau. Refugia adalah mikrohabitat yang menyediakan tempat berlindung secara spasial dan/atau temporal bagi musuh alami hama, seperti predator dan parasitoid, serta mendukung komponen interaksi biotik pada ekosistem, seperti polinator atau serangga penyerbuk. (Keppel et al., 2012).

Beberapa golongan tanaman refugia yang berasal dari famili Asteraceae seperti babadotan (Ageratum conyzoides), Ajeran (Bidens pilosa L.), Bunga tahi ayam (Tagetes erecta) sangat berpotensi sebagai mikrohabitat musuh alami di lahan. Widiastuti (2000) melaporkan bahwa serangga famili Coccinellidae lebih menyukai tumbuhan liar dari famili Asteraceae yakni Eupatorium odoratum dan Bidens pilosa. (Sinar Tani 2016).

Kegiatan ini bertujuan untuk meningkatkan pengetahuan kepada masyarakat kelompok tani wanita (KWT) Desa Laban, Mojolaban, Sukoharjo dalam optimalisasi budidaya TOGA dengan pembuatan pembuatan pestisida alami dari daun pepaya, serta memberikan pengetahuan dalam pemanfaatan refugia sebagai musuh alami organisme pengganggu tanaman. 


\section{METODE}

Pelaksanaan kegiatan pengabdian masyarakat di Desa Laban, Mojolaban, Sukoharjo dilaksanakan pada tanggal 9 Agustus hingga 4 September 2021. Peserta kegiatan adalah ibu-ibu Kelompok Wanita Tani Hijau Makmur sejumlah 35 peserta. Metode yang digunakan dalam pengabdian masyarakat ini adalah ceramah dan diskusi secara daring melalui whatsapp group. Kegiatan yang dilaksanakan meliputi beberapa tahap yaitu :

\section{Pretest}

Peserta diberikan 10 pertanyaan yang bertujuan untuk mengetahui adanya peningkatan pengetahuan ibu-ibu kelompok tani wanita (KWT) tentang optimalisasi budidaya TOGA dengan pembuatan pembuatan pestisida alami dan pemanfaatan refugia sebagai musuh alami organisme pengganggu tanaman.

2. Penyampaian materi

Pelaksaan penyuluhan disampaikan oleh pemateri sesuai tabel 1 dan dilanjutkan dengan tanya jawab dan diskusi antara pemateri dengan peserta.

Tabel 1. Rincian Pelaksanaan Penyuluhan

\begin{tabular}{lll} 
Waktu & Materi & Pemateri \\
\hline 15.00-16.00 & Optimalisasi & Apt. Iwan \\
& Pemanfaatan & Setiawan, \\
& dan & M.Sc. \\
& Budidaya di & \\
& TOGA di & \\
& Pekarangan & \\
& Rumah & \\
\hline $16.00-17.00$ & Pembuatan & Nastiti Utami, \\
& Pestisida & S.Si., M.Sc. \\
& Alami dari & \\
& Bahan di & \\
& Sekitar Kita & \\
\hline $17.00-18.00$ & Pemanfaatan & Prashinta \\
& Tanaman & Nita D, S.Si., \\
& Refugia & M.Pharm.Sci. \\
& sebagai & \\
& Pengendali & \\
Hama Alami & \\
\hline
\end{tabular}

4. Penyampaian Video Pembuatan Pestisida Alami dari Daun Pepaya

Setelah penyampaian materi, mahasiswa memutarkan video hasil praktik pembuatan pestisida alami dari daun pepaya agar peserta dapat praktik juga di rumah masing-masing.

5. Pembagian Bibit TOGA dan Tanaman Refugia

Untuk memaksimalkan fungsi lahan kebun pekarangan di area KWT Hijau Makmur, tim pengabdian membagikan bibit TOGA seperti jahe, keji beling, bidara, dan lain-lain agar dapat ditanam di lahan kebun pekarangan. Selain itu dibagikan pula tanaman refugia berupa bibit bunga matahari untuk mengendalikan hama di sekitar TOGA yang ditanam.

6. Monitoring dan Evaluasi

Monitoring dan Evaluasi dilaksanakan di akhir rangkaian acara kegiatan untuk mengetahui ada atau tidaknya peningkatan pengetahuan dan kepuasan peserta terhadap acara pengabdian ini.

\section{HASIL DAN PEMBAHASAN}

Kelompok wanita tani (KWT) Hijau Makmur yang berlokasi di Desa Laban, Mojolaban memiliki lahan pekarangan yang belum dimanfaatkan secara optimal oleh anggota kelompok wanita tani dalam pengelolaan lahan serta terdapat tanaman obat keluarga (TOGA) tidak tumbuh secara optimal. Pelaksanaan kegiatan dilakukan dengan penyuluhan dan pembagian benih TOGA dan tanaman refugia. Kegiatan ini dihadiri oleh lbu Sugiwahyem selaku ketua kelompok wanita tani (KWT) Hijau Makmur dan 34 anggota kelompok wanita tani (KWT) Hijau Makmur.

Penyuluhan dibagi menjadi 3 sesi, sesi pertama berisikan optimalisasi budidaya tanaman obat keluarga (TOGA) dan pemanfaatan TOGA terutama pada masa pandemi COVID-19, seperti dengan membuat minuman herbal atau jamu untuk meningkatkan daya tahan tubuh. Sesi kedua dijelaskan tentang kelebihan penggunaan pestisida alami, macam-macam tanaman/ bahan alami di sekitar kita yang ternyata dapat dimanfaatkan sebagai pestisida alami, serta cara pembuatan pestisida alami. Sesi ini semakin menarik diputarnya video pembuatan pestisida alami dari daun papaya oleh mahasiswa STIKES Nasional dengan harapan peserta penyuluhan dapat praktik membuat pestisida alami tersebut di rumah masing-masing.

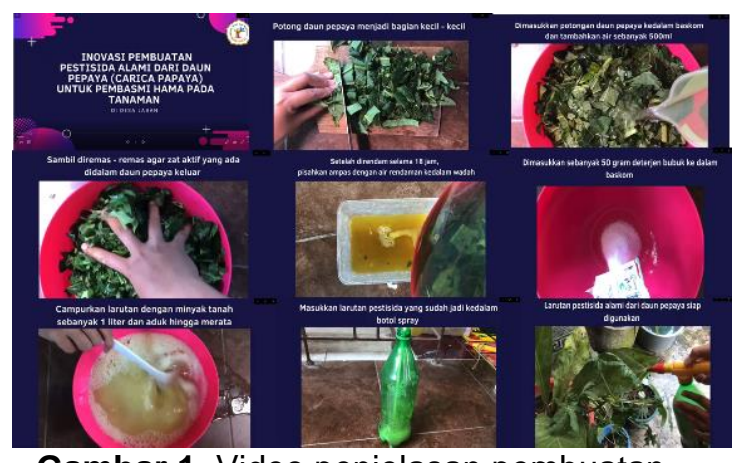

Gambar 1. Video penjelasan pembuatan pestisida alami

Selanjutnya pada sesi ketiga dijelaskan mengenai pemanfaatan tanaman refugia sebagai pengendali hama alami, macammacam tanaman refugia serta cara penanaman dan perawatan tanaman refugia. 


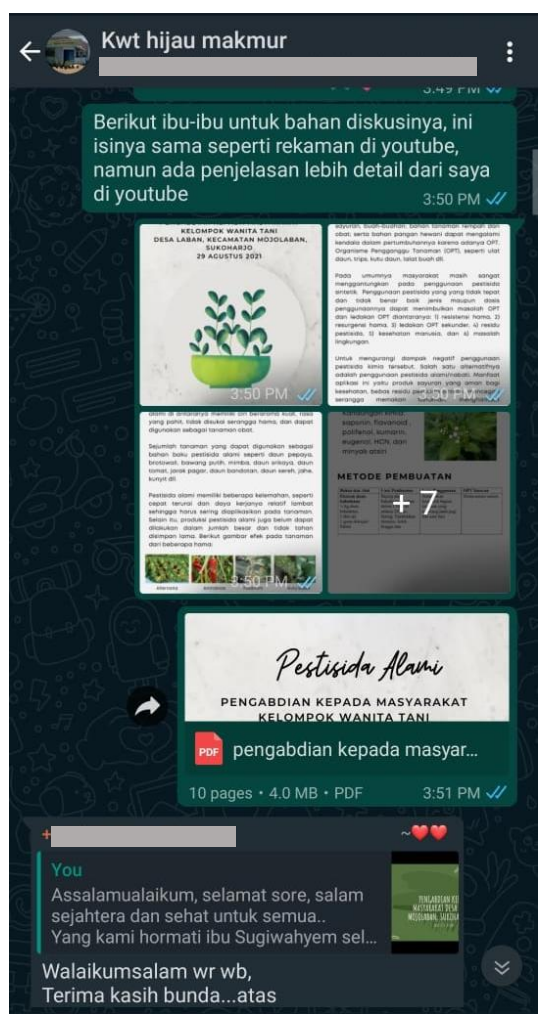

Gambar 2. Penyampaian materi penyuluhan via whatsapp group

Gambar 2. menjelaskan pemaparan masingmasing materi dilakukan dengan mengirimkan foto-foto slide materi dan video penjelasannya melalui whatsapp group agar peserta dapat lebih memahami materi yang disampaikan. Peserta juga mendapatkan buku saku berbentuk hardfile agar lebih mudah dibaca dan dipahami. Acara diskusi dan tanya jawab pada Gambar 3 berlangsung dengan sangat aktif dikarenakan belum banyak masyarakat yang memanfaatkan bahan alami dan tanaman refugia untuk membasi dan mengendalikan hama tanaman.

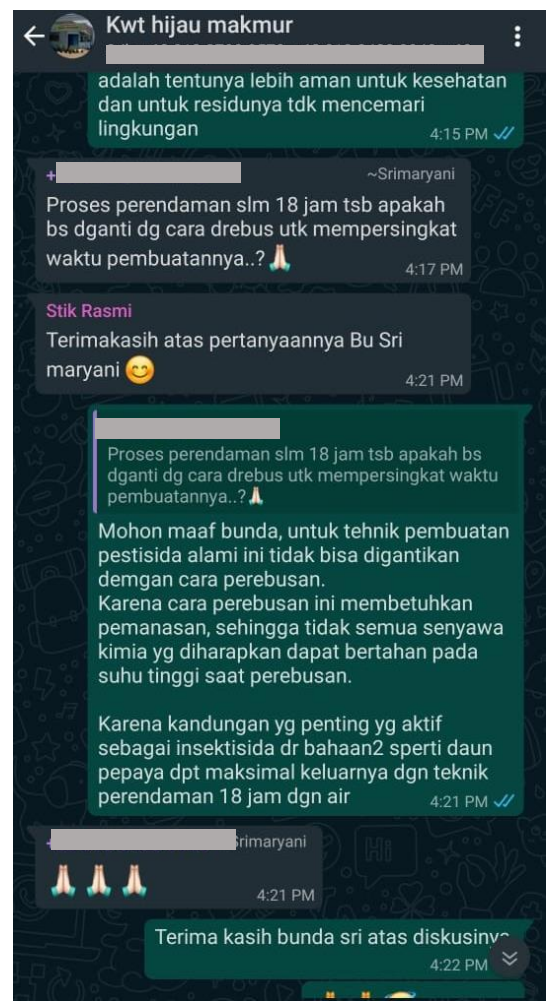

Gambar 3. Suasana diskusi dan tanya jawab

Selain penyuluhan ada pula pembagian bibit tanaman obat keluarga (TOGA) seperti jahe, kencur, kunyi, sirih hijau, keji beling, daun ungu dan lain-lain serta tanaman refugia yaitu bunga kertas dan bunga matahari (Gambar 4). Dengan adanya pembagian TOGA diharapkan dapat meningkatkan fungsi lahan kebun pekarangan dan meningkatkan kualitas kesehatan masyarakat. Pembagian tanaman refugia diharapkan dapat mengendalikan hama di sekitar tanaman TOGA sehingga TOGA dapat tumbuh lebih optimal.

Berikut ini dokumentasi kegiatan pembagian bibit tanaman obat keluarga dan benih tanaman refugia kepada kelompok wanita tani (KWT) Hijau Makmur.

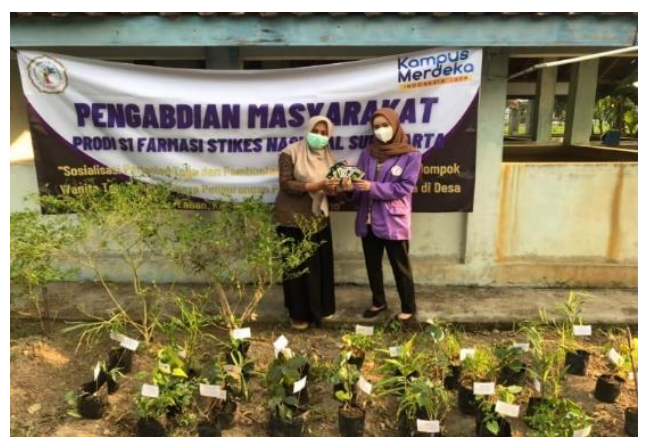

Gambar 4. Pembagian bibit tanaman obat keluarga (TOGA) dan tanaman refugia kepada kelompok wanita tani (KWT)

Kegiatan pengabdian masyarakat yang dilakukan secara daring ini diawali dan diakhiri 
dengan adanya pretest dan posttest yang bertujuan mengetahui adanya peningkatan pengetahuan ibu-ibu kelompok tani wanita (KWT) tentang materi yang disampaikan. Dari data nilai pretest dan posttest terlihat adanya peningkatan nilai yang didapatkan sesudah pengabdian dilakukan, yaitu nilai rata-rata untuk pretest sebesar 53,71 dan rata-rata posttest sebesar 84,00 dengan perbedaan rata-rata pretest dan posttest sebesar 30,29. Nilai signifikansi (2-tailed) $0.000<0,05$ menunjukkan adanya perbedaan yang signifikan antara variabel awal dengan variabel akhir.

Evaluasi juga dilakukan untuk melihat tingkat kepuasan peserta kegiatan pengabdian yang dilaksanakan pada kegiatan dan tema yang diambil. Hasil kuosioner menunjukkan $42,9 \%$ peserta menyatakan sangat puas, $48,6 \%$ peserta menyatakan puas, dan $8,6 \%$ peserta menyatakan cukup puas dengan kegiatan dan tema pengabdian masyarakat ini.

\section{SIMPULAN DAN SARAN}

Penyuluhan tentang optimalisasi budidaya tanaman obat keluarga (TOGA) dengan pembuatan pembuatan pestisida alami dari daun papaya serta pemanfaatan tanaman refugia sebagai pengendali hama tanaman telah dilakukan di Desa Laban, Kecamatan Mojolaban, Kabupaten Sukoharjo dengan peserta ibu-ibu Kelompok Wanita Tani (KWT) Hijau Makmur berjumlah 35 orang. Dengan adanya pengabdian masyarakat ada peningkatan pengetahuan peserta dilihat dari adanya peningkatan nilai pretest yang semula 53,71 menjadi 84,00. Hasil evaluasi juga menyatakan bahwa dari 35 peserta, 42,9\% peserta menyatakan sangat puas, $48,6 \%$ peserta menyatakan puas, dan $8,6 \%$ peserta menyatakan cukup puas dengan kegiatan dan tema pengabdian masyarakat ini.

Program pengabdian mengenai pemanfaatan pestisida alami dan pemanfaatan tanaman refugia sebagai pengendali hama diharapkan dapat terus dilaksanakan di lokasilokasi lain mengingat masih banyaknya masyarakat yang menggunakan pestisida kimiawi untuk bahan pangan.

\section{UCAPAN TERIMAKASIH}

Penulis mengucapkan terima kasih kepada Kementerian Pendidikan, Kebudayaan, Riset, dan Teknologi yang telah memprakarsai Program Kompetisi Kampus Merdeka sehingga memfasilitasi adanya Program Pengabdian Kolaboratif antara Dosen dan Mahasiswa STIKES Nasional. Ucapan terima kasih juga kami ucapkan kepada Kepala Desa beserta segenap warga Laban, Mojolaban, Sukoharjo.

\section{DAFTAR RUJUKAN}

Aqilah, A.R., (2016). Pengaruh Tanaman Refugia dalam Meningkatkan Populasi dan. Diversitas Musuh Alami Wereng Batang Coklat, Skripsi: Program Studi.

Hasfita Fikri, Nasrul ZA dan Lafyati. (2019). Pemanfaatan Daun Pepaya (Carica papaya) untuk Pembuatan Pestisida Nabati. Journal Teknologi Kimia. Aceh : Universitas Malikussaleh.

Keppel, G., K.P. Van Niel, G.W. WardellJohnson, C.J. Yates, M.Byrne, L. Mucina, A.G.T. Schut, S.D. Hopper, dan S.E. Franklin. (2012). "Refugia: Identifying and understanding safe havens for biodiversity under climate change." Global Ecology and Biogeography 21 (4): 393-404. doi:10.1111/j.1466- 8238.2011.00686.x

Lestari, S., Roshayanti, F., \& Purnamasari, V. (2019). Peningkatan Ekonomi Keluarga Melalui Pemanfaatan Tanaman Toga Sebagai Jamu Keluarga. International Journal of Community Service Learning, 3(1), 22-26.

Muchlisah, F. (2004). Tanaman Obat Keluarga (TOGA). Penebar Swadaya. Jakarta.

Nentwig, W. (1998). Weedy plant spesies and their beneficial arthropod: potential for manipulation in field crops, p 49-72. In C.H. Pickett \& R.L. Bugg (eds), Enhancing Biological Control. University of Calivornia Press. Los Angeles.

Savitri A. (2016). Tanaman Ajaib Basmi Penyakit dengan TOGA (Tanaman Obat Keluarga) Mengenali Ragam dan Khasiat TOGA Meramu Jamu Tradisional/ Herbal dengan TOGA. Bibit Publisher,Depok.

Septariani, D. N., Herawati, A. and Mujiyo, M. (2019) 'Pemanfaatan Berbagai Takman Refugia Sebagai Pengendali Hama Alami Pada Tanaman Cabai (Capsicum annum L.)', PRIMA: Journal of Community Empowering and Services, 3(1), $\quad$ p. $1 . \quad$ doi: 10.20961/prima.v3il.36106

Sinar Tani. (2016). "Refugia bukan sekedar penghias sawah". Sinar Tani Edisi 1218 Oktober 2016. No. 3674. Tahun XLVII.

Yogiraj, V. Goyal, P.K. Chauhan, C.S. Carica, (2015). papaya Linn : An Overview.;2(5):1-8. 